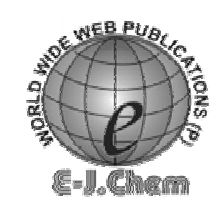

http://www.e-journals.net
ISSN: 0973-4945; CODEN ECJHAO

E-Journal of Chemistry

Vol. 1, No. 2, pp 110-114, April 2004

\title{
Synthesis and Characterization of Some Trivalent and Tetravalent Derivatives of 2- Hydroxy-1-naphthoic Acid
}

\author{
DEEPTI JOSHI* and T. K. JOSHI ${ }^{\S}$ \\ "Chemical Laboratories, \\ DSB Campus, Kumaun University, \\ Nainital-263002, Uttranchal (INDIA). \\ ${ }^{\S}$ Chemistry Department.CBS\&H, G.B.Pant. \\ University of Agriculture and Technology. Pantnagar. \\ deeptiajoshi@yahoo.co.in \\ Received 22 February 2004; Accepted 10 March 2004

\begin{abstract}
The trivalent derivatives (B, $\mathrm{Al}, \mathrm{As}, \mathrm{Sb} \& \mathrm{Fe}$ ) and tetravalent derivatives (Si,Ti \& Se) of 2-hydroxy-1-naphthoic acid have been prepared by the interaction of their corresponding isopropoxide with letter in different molar ratio viz. 1:3 $\& 1: 4$ in benzene medium. The prepared compounds generally obtained as coloured solids and amongst them those containing isopropoxy groups were found to be hygroscopic. All these compound were characterized by azeotrope and elemental analysis as well as by IR, PMR and mass spectral measurements. These spectral data have facilitated in elucidating the mode of bonding of the said metals and nonmetals in these compounds with 2-hydroxy-1-naphthoic acid.
\end{abstract}

Keywords: Tri- and tetravalent derivatives, 2-Hydroxy-1-naphthoic acid, Alcoholysis reaction.

\section{Introduction}

The reactivity of metal / non metal alkoxides provides a simple and convenient method for preparations of a variety of metallo-organic / non-metallo-organic compounds.

The ligating properties of 2-hydroxy-1-naphthoic acid containing hydroxy groups $(-\mathrm{OH})$ adjacent to the carboxylic acid group $(-\mathrm{COOH})$ have seen extensively examined ${ }^{1-3}$ owing to the favorable geometry of donor sites for stable 6-membered metal chelating ring formation. 
These prepared trivalent and tetravalent compounds of 2-hydroxy-1-naphthoic acid (abbreviated as 2,1hna or $\mathrm{LH}_{2}$ ) (structure a) by alcoholysis reaction involving the interaction of the corresponding metal/non-metal isopropoxide with $2,1 \mathrm{hna}$ in appropriate stoichiometric ratios viz. 1:3 and 1:4 (1:1 and 1:2 were reported earlier $\left.{ }^{4}\right)$ in benzene as a reaction medium.

\section{Experimental}

\section{Materials}

All the chemicals used during the study were of analytical grade reagents. The solvents were dried by standard procedures. ${ }^{5}$ 2-Hydroxy-1-napthoic acid were used after re-crystallization from 50\% (v/v) aqueous ethanol. B, Al, Fe, As or $\mathrm{Sb}$ triisopropoxides and $\mathrm{Si}$ and $\mathrm{Se}$ tetraisopropoxides were prepared by already reported methods ${ }^{6}$. Titanium tetraisopropoxides were used as such.

\section{General Procedure for the synthesis of trivalent and tetravalent derivatives}

The tri/tetravalent isopropoxide and 2,1 hna in appropriate stoichiometry in dry benzene are refluxed on a wax bath at $90-100^{\circ} \mathrm{C}$. After several hrs (Table 1) of reflux, the isopropanolbenzene was fractionated out and the amount of isopropanol liberated was estimated by an oxidimetric method $^{7,8}$ to monitor the completion of the reaction. This yielded colored solid which was washed with dry benzene followed by dry ether and finally dried under suction.

\section{Characterization}

Melting points were recorded on an electro thermal CAT No. IA 8103 digital m.p. apparatus. The IR spectra was recorded on a Bruker IFS 66 v FT-IR spectrometer, using $\mathrm{KBr}$ pellets in the region $4000-400 \mathrm{~cm}^{-1}$, while the PMR spectra were taken in DMSO- $\mathrm{d}_{6}$ solution and recorded on a JEO GSX $400 \mathrm{NB}$ FT-NMR $400 \mathrm{MHz}$ spectrometer, using TMS as an internal standard. The electrospray mass spectra were recorded on a Micromass Quatro II triple quadrapole mass electrospray spectrometer.

\section{Results and Discussion}

The reaction occurring between tri and tetravalent metal and non- metal isopropoxide and $\mathrm{LH}_{2}$ may be illustrated as under:

$$
\begin{aligned}
& \begin{array}{l}
\mathrm{M}\left(\mathrm{OPr}^{\mathrm{i}}\right)_{3}+3 \mathrm{LH}_{2} \\
(\mathrm{Where} \mathrm{M}=\mathrm{Bi}, \mathrm{Al}, \mathrm{Fe}, \mathrm{As} \mathrm{\&} \mathrm{Sb})
\end{array} \\
& \begin{array}{l}
\mathrm{M}\left(\mathrm{OPr}^{\mathrm{i}}\right)_{4}+3 \mathrm{LH}_{2} \\
\left.\mathrm{M}\left(\mathrm{OPr}^{\mathrm{i}}\right)_{4}+4 \mathrm{LH}_{2}\right)_{3}+3 \operatorname{Pr}^{\mathrm{i} O H} \\
(\mathrm{M}=\mathrm{Si}, \mathrm{Ti} \& \mathrm{Se})
\end{array}
\end{aligned}
$$

\section{IR and PMR spectrum of trivalent (III) and tetravalent (IV) compounds ${ }^{9,11}$}

The IR and PMR spectrum are already known ${ }^{4}$. M(III) $\left(\mathrm{LH}_{2}\right)_{3}, \mathrm{M}(\mathrm{IV})\left(\mathrm{LH}_{2}\right)_{4}$ shows weak and medium absorption in the region $3100-2880 \mathrm{~cm}^{-1}$ indicate the overlapping of free hydroxy and $\mathrm{vC}-\mathrm{H}$ of the aromatic ring, while the other absorptions in the region 3100$2880 \mathrm{~cm}^{-1}$ corresponds to the overlapping of $\mathrm{v} \mathrm{C}-\mathrm{H}$ of the aromatic ring and isopropoxide group in case of $\mathrm{M}(\mathrm{IV})\left(\mathrm{LH}_{2}\right)_{3}\left(\mathrm{OPr}^{\mathrm{i}}\right)$. The absorption in the region $1645-1620 \mathrm{~cm}^{-1}$ shows the overlapping of $v_{\mathrm{as}} \mathrm{COO}$ and $v \mathrm{C}=\mathrm{C}$ of the aromatic ring and other absorption at $1440-1420 \mathrm{~cm}^{-1}$ assigned to $v_{\mathrm{s}} \mathrm{COO}$ of the carboxylate group. Thus a shift of $10-20$ $\mathrm{cm}^{-1} v_{\mathrm{s}} \mathrm{COO}$ in comparison to the ligand suggests bonding of the carboxylate oxygen to the corresponding metal / non-metal. Further the separation value $\left(v_{\mathrm{as}} \mathrm{COO}-\mathrm{v}_{\mathrm{s}} \mathrm{COO}\right)$ 
$\Delta v \mathrm{COO}, 185-230 \mathrm{~cm}^{-1}$ suggests the presence of a bridged or coordinated carboxylate group. The weak absorptions in the region $1390-1360 \mathrm{~cm}^{-1}$ in $\mathrm{M}(\mathrm{IV})(\mathrm{LH})_{3}\left(\mathrm{OPr}^{\mathrm{i}}\right)$ exhibits $\mathrm{C}-\mathrm{H}$ bending of the gem-dimethyl structure of the isopropoxy group and other absorption in the region 1345-1210 $\mathrm{cm}^{-1}$ because of the $\mathrm{v} \mathrm{C}-\mathrm{O}$ of the hydroxyl group, while the absorption in the region $1160-1140 \mathrm{~cm}^{-1}$ in $\mathrm{M}(\mathrm{IV})\left(\mathrm{LH}_{2}\right)_{3}\left(\mathrm{OPr}^{\mathrm{i}}\right)$ correspond to $\mathrm{vC}-\mathrm{O}$ of the isopropoxy group. The new bands around $1360-1350 \mathrm{~cm}^{-1}$ and $580-475 \mathrm{~cm}^{-1}$ correspond to $\mathrm{vB}-\mathrm{O}$ and $v \mathrm{M}-\mathrm{O}(\mathrm{M}=\mathrm{Br}, \mathrm{Al}, \mathrm{Sb}, \mathrm{Fe}, \mathrm{As}, \mathrm{Si}$, Ti \&, Se).

Table 1. Analytical details of the compounds of 2-hydroxy-1-naphthoic acid.

\begin{tabular}{|c|c|c|c|c|c|c|c|}
\hline S.No & $\begin{array}{l}\text { Compound } \\
\text { molar ratio }\end{array}$ & $\begin{array}{l}\text { Reflux } \\
\text { time, h }\end{array}$ & Colour & ${ }^{\mathrm{M}} \mathrm{C}$ & $\begin{array}{c}\text { Azeotrope } \\
\text { Analysis } \\
\text { Found, Cald. }\end{array}$ & $\begin{array}{l}\mathrm{C} \% \mathrm{H} \% \mathrm{M} \% \\
\text { Found Found Found, } \\
(\mathrm{Cal}),(\mathrm{Cal}),(\mathrm{Cal}) .\end{array}$ & $\begin{array}{c}\text { Mol. } \\
\text { Weight* }\end{array}$ \\
\hline 1 & $\begin{array}{c}\mathrm{B}\left(\mathrm{LH}_{2}\right)_{3} \\
(1: 3)\end{array}$ & 06 & $\begin{array}{l}\text { Light } \\
\text { yellow }\end{array}$ & 240 & $\begin{array}{c}0.87 \\
(0.87)\end{array}$ & $\begin{array}{rll}68.20 & 2.80 & 0.80 \\
(69.25) & (3.69) & (1.90)\end{array}$ & 572.35 \\
\hline 2 & $\begin{array}{l}\mathrm{Al}\left(\mathrm{LH}_{2}\right)_{3} \\
\quad(1: 3)\end{array}$ & 08 & Brown & 270 & $\begin{array}{c}0.98 \\
(0.98)\end{array}$ & $\begin{array}{ccc}66.25 & 2.50 & 3.45 \\
(67.35) & (3.60) & (4.58)\end{array}$ & 588.51 \\
\hline 3 & $\begin{array}{l}\mathrm{Fe}\left(\mathrm{LH}_{2}\right)_{3} \\
\quad(1: 3)\end{array}$ & 12 & Black & 300 & $\begin{array}{c}0.50 \\
(0.50)\end{array}$ & $\begin{array}{ccc}63.30 & 2.30 & 8.04 \\
(64.20) & (3.43) & (9.04)\end{array}$ & 617.38 \\
\hline 4 & $\begin{array}{l}\mathrm{As}\left(\mathrm{LH}_{2}\right)_{3} \\
\quad(1: 3)\end{array}$ & 08 & Yellow & 220 & $\begin{array}{c}0.71 \\
(0.71)\end{array}$ & $\begin{array}{rrr}61.50 & 2.30 & 10.70 \\
(62.28) & (3.33) & (11.77)\end{array}$ & 636.44 \\
\hline 5 & $\begin{array}{l}\mathrm{Sb}\left(\mathrm{LH}_{2}\right)_{3} \\
\quad(1: 3)\end{array}$ & 10 & White & 250 & $\begin{array}{l}1.07 \\
(1.08)\end{array}$ & $\begin{array}{rl}4.30 & 2.1016 .80 \\
(58.00) & (3.09)(17.81)\end{array}$ & 683.29 \\
\hline 6 & $\begin{array}{l}\mathrm{Si}\left(\mathrm{LH}_{2}\right)_{3} \\
\left(\mathrm{Opr}^{1}\right) \\
(1: 3)\end{array}$ & 10 & White & 270 & $\begin{array}{c}1.62 \\
(1.63)\end{array}$ & $\begin{array}{c}65.603 .353 .70 \\
(66.65)(4.35)(4.33)\end{array}$ & 648.71 \\
\hline 7 & $\begin{array}{l}\mathrm{Si}\left(\mathrm{LH}_{2}\right)_{4} \\
\quad(1: 4)\end{array}$ & 12 & Off white & 280 & $\begin{array}{l}1.98 \\
1.99\end{array}$ & $\begin{array}{c}67.502 .632 .60 \\
(68.04)(3.63)(3.60)\end{array}$ & \\
\hline 8 & $\begin{array}{c}\mathrm{Ti}\left(\mathrm{LH}_{2}\right)_{3} \\
\left(\mathrm{OPr}^{1}\right)(1: 3)\end{array}$ & 09 & $\begin{array}{l}\text { Reddish } \\
\text { brown }\end{array}$ & 260 & $\begin{array}{c}1.00 \\
(1.01)\end{array}$ & $\begin{array}{c}63.233 .352 .55 \\
(64.68)(4.23)(7.17)\end{array}$ & 668.52 \\
\hline 9 & $\begin{array}{c}\operatorname{Ti}\left(\mathrm{LH}_{2}\right)_{4} \\
(1: 4)\end{array}$ & 10 & $\begin{array}{l}\text { Reddish } \\
\text { brown }\end{array}$ & 240 & $\begin{array}{c}0.81 \\
(0.82)\end{array}$ & $\begin{array}{rrr}65.98 & 2.10 & 5.24 \\
(66.34) & (3.54) & (6.01)\end{array}$ & \\
\hline 10 & $\begin{array}{c}\mathrm{Se}\left(\mathrm{LH}_{2}\right)_{3} \\
\left(\mathrm{OPr}^{1}\right)(1: 3)\end{array}$ & 08 & Off white & 230 & $\begin{array}{c}0.58 \\
(0.58)\end{array}$ & $\begin{array}{c}60.803 .1010 .10 \\
(61.81)(4.03)(11.29)\end{array}$ & \\
\hline 11 & $\begin{array}{l}\mathrm{Se}\left(\mathrm{LH}_{2}\right)_{4} \\
\quad(1: 4)\end{array}$ & 08 & Off white & 230 & $\begin{array}{c}0.73 \\
(0.73)\end{array}$ & $\begin{array}{rll}62.70 & 2.30 & 8.60 \\
(63.85) & (3.41) & (9.54)\end{array}$ & \\
\hline
\end{tabular}

* Molecular weight obtained by Mass Spectrum in several representative cases.

The multiplet between 7.20-8.15 corresponds to the naphthyl ring protons. The doublet and multiplet in the region 1.20-1.55 and 4.10-4.55 due to $-\mathrm{CH}_{3}$ and $\equiv \mathrm{CH}$ protons of the isopropoxy group in $\mathrm{M}(\mathrm{IV})\left(\mathrm{LH}_{2}\right)_{3}\left(\mathrm{OPr}^{\mathrm{i}}\right)$. A hump in the region 6.44-5.85 suggests that the hydroxy group remains intact. The signal due to the protons of the carboxylic acid observed in $2.1 \mathrm{hna}$ disappear in these compounds and no additional peaks have been observed to occur which indicates the participation of carboxylate groups in bonding with the corresponding metal / non-metal. 


\section{Structural Aspects}

On the basis of azeotrope and elemental analysis, as well as spectral data of compounds, the main findings of the structures of synthesized compounds are as under.

The compounds $\mathrm{M}\left(\mathrm{LH}_{2}\right)_{3}$ ( where $\mathrm{M}=\mathrm{B}, \mathrm{Al}, \mathrm{Fe}, \mathrm{As} \& \mathrm{Sb}$ ) contain hexa-coordinated atom in each case as a result of bonding with both the oxygens from each of the three carboxylate groups available from three moles of 2,1 hna.( structure b).

The compounds $\mathrm{M}\left(\mathrm{LH}_{2}\right)\left(\mathrm{OPr}^{\mathrm{i}}\right)$ (Where $\mathrm{M}=\mathrm{Si}$, Ti \& Se) contain hepta coordinated atom in each case as a result of bonding with both the oxygens from each of the three carboxylate groups available from three moles of 2,1 hna along with an isopropoxy group (structure c) and $\mathrm{M}\left(\mathrm{LH}_{2}\right)_{4}$ compounds ( where $\mathrm{M}=\mathrm{Si}$, Ti \& Se)contain octa coordinated atom as a result of bonding with both the oxygens from each of the four carboxylate groups available from four moles of 2,1 hna ( structure d).<smiles>O=C(O)c1c(O)ccc2ccccc12</smiles><smiles>Cc1c(O)ccc2ccccc12</smiles>

Structure-a

Structure-b<smiles>Cc1cc2ccc(O)c(C)c2cc1O</smiles>

Structure-c

Structure-d

a $\quad \mathrm{LH}_{2}(2,1 \mathrm{hna})$

b Where $\mathrm{M}=\mathrm{B}, \mathrm{Al}, \mathrm{Fe}, \mathrm{As} \& \mathrm{Sb}$

c Where $\mathrm{M}=\mathrm{Si}$, Ti, Se

d Where $\mathrm{M}=\mathrm{Si}, \mathrm{Ti}, \mathrm{Se}$

\section{References}

1. Pachauri O P and Tandon J P Bull. Acad. Pol. Sci. Ser. Sci. chem, 197422981

2. Dwivedi K, Chandra M and Dey A K Transition Metal Chem, 19772186

3. Datta P K, Chandra M and Dey A K Transition Metal chem, 198051

4. Pandey H, Joshi D, Pant D and Chandra M Chem. Environ. Res, 200110 
5. Vogal A I Text Book of Practical Organic chemistry, $4^{\text {th }}$ Ed. Longman, London. 1978

6. Bradley D C, Gaur D P, Mehrotra R C and Metal Alkoxides, Academic Press, London 1978

7. Mehrotra R C J. Indian Chem. Soc, 195431904

8. Bradley D C, Halim F M A and Wardlaw W J. Chem. Soc, 1987 26A 158

9. Bellamy I. J The Infrared Spectra of Complex Molecules, Methuon. London. 1962

10. Nakamoto K. Infrared and Raman Spectra of Inorganic and Coordination Compounds, John wiley. New York, 1978

11. Silverstein R M, Bassler G C and Morrill J C Spectroscopic Identification of Organic Compounds. John Wiley. New York, 1981 


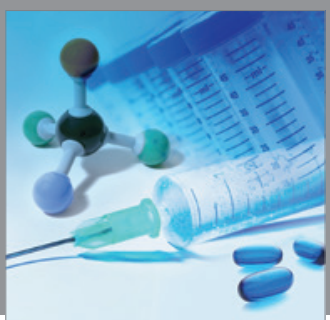

International Journal of

Medicinal Chemistry

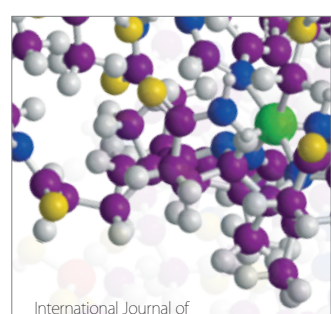

Carbohydrate Chemistry

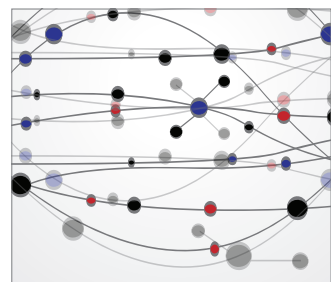

The Scientific World Journal
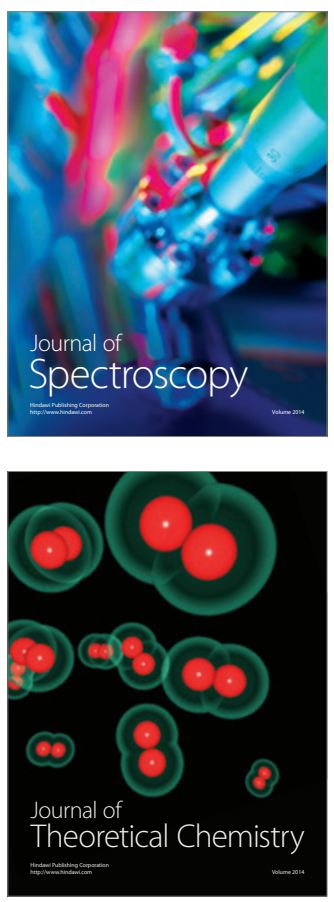
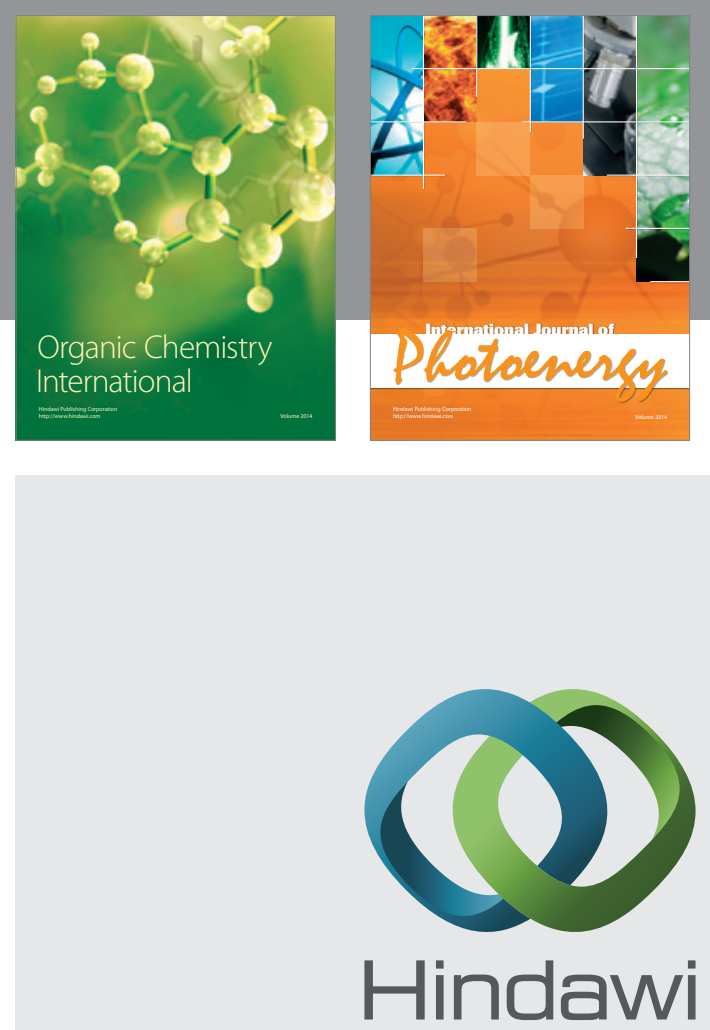

Submit your manuscripts at

http://www.hindawi.com
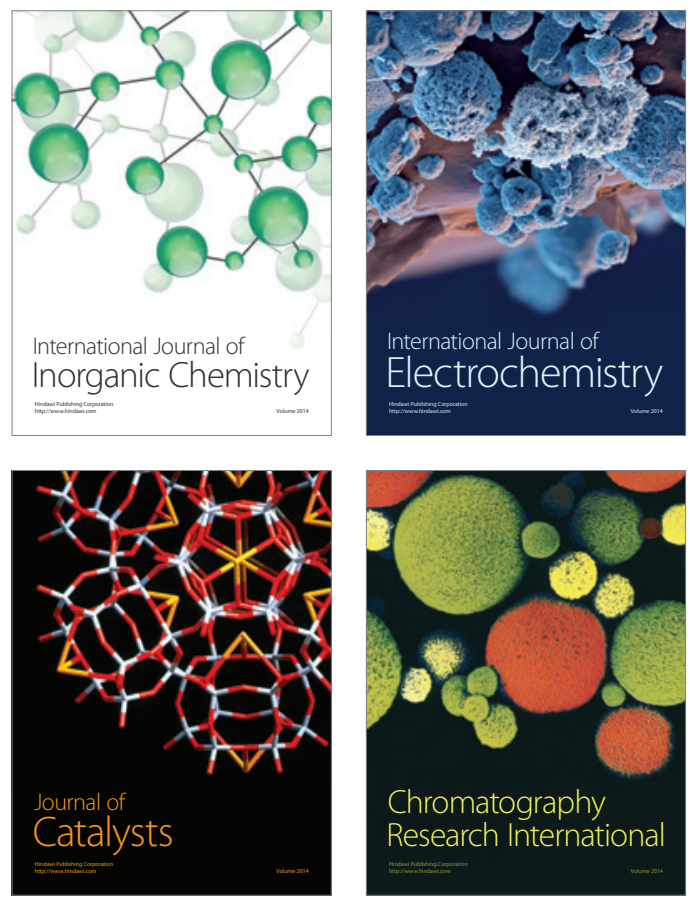
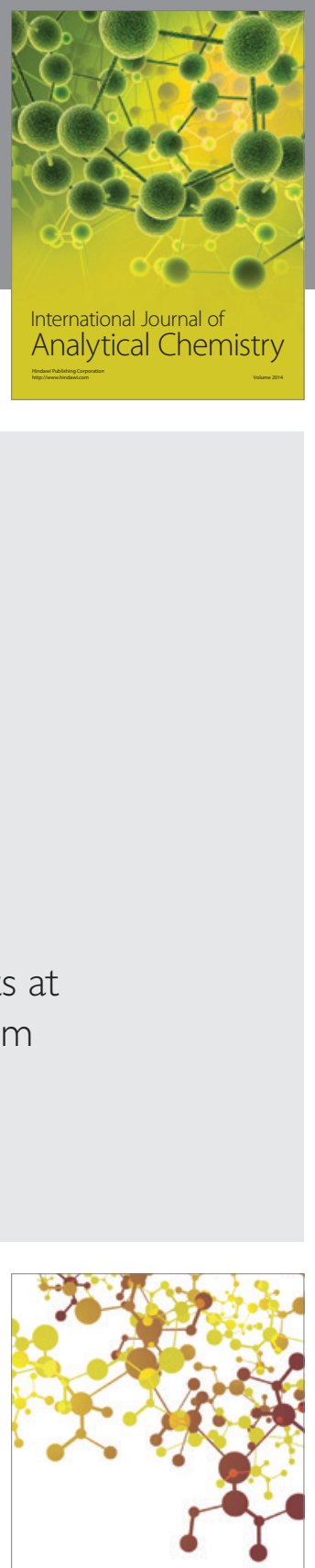

Journal of

Applied Chemistry
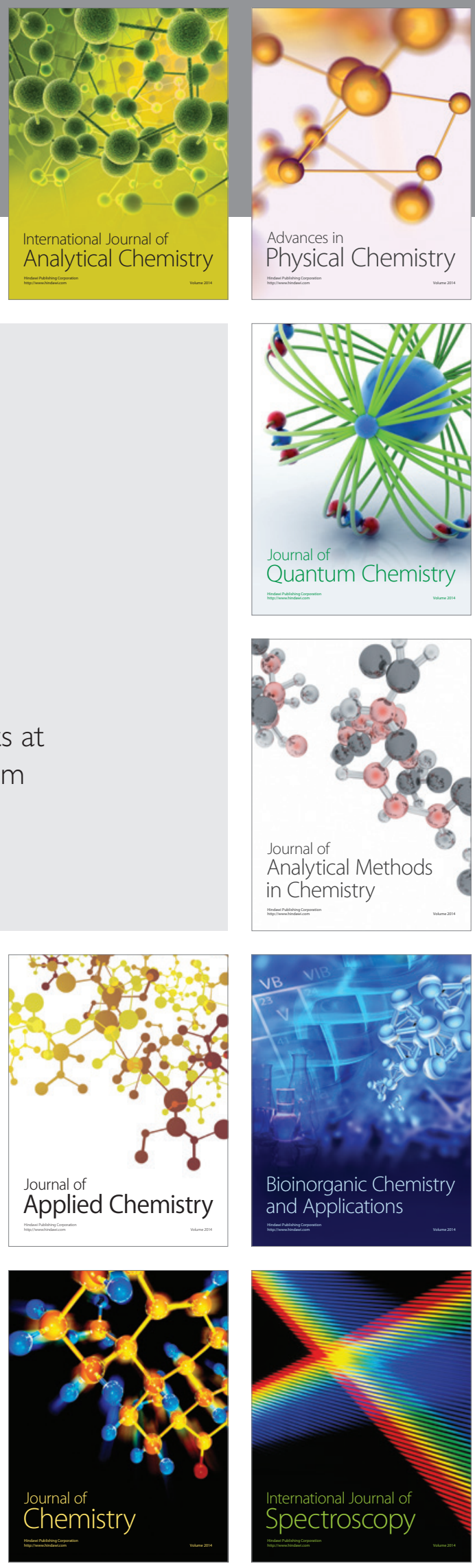